\title{
Drawings as a method of evaluation and communication with bereaved children
}

\author{
Nomahlubi V. Makungal \\ and \\ Lindiwe O. Shange ${ }^{2}$ \\ Department of Psychology, University of Zululand \\ nmakunga@pan.uzulu.ac.za
}

\begin{abstract}
There is much concern over childhood grief when death strikes in the child's immediate environment. If the experience of bereavement can be reliably measured in children, insight into their painful experiences will be gained and appropriate treatment strategies will be established.

This study aimed to explore whether projective drawings could provide a reliable method of exploring the world of a black bereaved child. The Human Figure Drawing (HFD), Self Portrait, Kinetic Family drawing (KFD) and Own Choice/ spontaneous Drawing techniques were administered with a group of 20 bereaved children and a control group of 20 non bereaved children. In general, more emotional indicators were identified on HFDs and Self Portraits of the Bereaved Group. Results showed statistically significant differences between the two groups on four indicators in HFDs (big figure; teeth; monster/grotesque; hands cut off) and on two indicators in Self Portrait (slanting figure and hands cut off) KFDs and Own Choice Drawings could not statistically differentiate the two groups but were found to be of assistance in gaining insight into the family dynamics and for improving grief work respectively, in the bereaved group. Composite analysis of the four projective drawings provided more insight into the world of the bereaved child
\end{abstract}

Keyword: Drawings; method; evaluation; communication; bereaved children, psychology.

\section{Introduction}

This article is motivated by the concern as to whether children complete the grief process when death occurs in their immediate environment. This concern relates to the popular assumption that children do not really understand death, the belief that children should not be involved in situations which concern death and the consequent neglect that chidren may experience during times of bereavement (McMahon, 1992; Hemmings, 1995, Siegel, Mesagno \& Christ, 1990; Worden, 1986).

Research suggests that children do present with grief reactions in the form of behaviour following attachment loss (Bowlby, 1980; Worden, 1986; Case, 1987; Forrest \& Thomas, 1991). Forrest and Thomas (199I) have documented that the emotional pain experienced by bereaved children may at times be unrecognized and therefore unresolved. Christ, Siegel, Mesagno and Langosch (1991) suggest that psychosocial development and mental health of children may be affected by the death in the child's family or immediate environment. Thus, helping children deal with the suggested emotional pain caused by bereavement will improve childhood health and lead to long term psychological well being in adulthood. Mental health professionals, psychologists in particular, can contribute towards identifying and assisting bereaved children through the implementation of effective intervention strategies.

Children often find it very difficult to articulate their feelings verbally (Worden, 1986; McMahon, 1992). Research (Siegel, 1960; Forrest \& Thomas, 1991) has shown that many children express painful experiences effectively through drawings, a medium of expression experienced as easier than verbal articulation. Supporting the notion that drawing is a natural mode of expression, Koppitz (1983) stated the following: "During the elementary school years boys and girls can express their thoughts and feelings often better in visual images than in words" (p.2). Much research has recognized the value of using drawings to help children express problems and worldly-views (Burns, 1982; Golomb, 1992; Koppitz, 1968; Klepsch \& Logic, 1982; Winnicott, 197I). Therapists introduce drawings to facilitate communication, expression, and assessment. Kelly $(1984 ; 1985)$ argues particularly for human figure drawings as emotional assessment indicators to identify trauma in young children, who are unable to verbalize their feelings. Cantlay (1996) suggests that both distress and trauma can be expressed and identified in drawings.

In addition to helping children express their feelings of grief, drawings assist the process of healing. The overall purpose of this study was to identify bereaved feelings expressed in children's drawings.

I. Nomahlubi Makunga, D Litt et Phil, is Executive Dean of the Faculty of Arts, University of Zululand, South Africa.

2. Lindiwe Shange completed her PhD in Community Psychology in the the Department of Psychology, University of Zululand, South Africa 


\section{Method}

Aim

This study had three aims: firstly to report findings concerning grief which children experience when they lose an immediate family member; secondly to clarify the relationship between projective drawings and expressions of an affective meaning in life and thirdly, to assess the inner world, individual feelings and personality structures of bereaved children through drawings.

\section{Hypothesis}

It was expected that children's drawings would provide sufficient information about emotional states to distinguish the bereaved children's group from a matched control group

\section{Participants}

Forty children who attended primary school in the KwaZulu-Natal province participated in the study. All participants were Zulu speaking (one of the largest Southern African language groups). Group A (experimental) consisted of 20 bereaved children and a matched group B (control) consisted of 20 non-bereaved children.

The larger sample was chosen to extend earlier research done using projective drawings with small samples of children (Siegel 1960). None of the 40 subjects had any significant history of psychological disorder. For the total sample, ages ranged from 8 to 12 years. Inclusion in the experimental group meant that the bereaved child had lost a parent or sibling in the past six months.

The present study used a non-probability convenience and purposive sample (Bailey., 1978; Reaves, 1992; Schweigert, 1988). As suggested by Bailey (1978), research projects, often use non-probability samples despite the drawbacks that arise from their non-representativeness. This is due to the fact that they are less expensive, easier to use and are adequate for non-generalizing purposes.

\section{Measuring instruments}

The data were collected using a series of qualitative individual interviews and psychological assessments. Literature by Harris, (1963); Koppitz, (1968) and Mayekiso, (1982) has emphasized the importance of using individual assessment together with projective drawings, as individual assessments provide a more thorough observation and understanding of the individual during the drawing process and allow for the opportunity to clarify questions about the drawn figures. As suggested by Koppitz (1968) an attempt was made to provide an environment that was comfortable and uncluttered. No pictures were placed on the walls as this could have served as models which the children may have copied.

Well known psychological instruments which have been used extensively with children were utilized. They were easy to administer and were well tolerated by all participants. The interviews and assessments took place over a period of six months. Informed consent was obtained from each participant's parent/guardian. Letters of informed consent were written in Zulu to accommodate the overwhelming majority of the parents who were Zulu speaking and mostly with a primary school education. All interviews and instructions with the participants were given in Zulu to prevent any misunderstanding. The research design incorporated the use of both descriptive and inferential analyses.

According to Hammand and Grantt (1998) art work (including projective drawings) produced by clients should be protected in the same confidential manner as verbal communication. Protocols were therefore not identified by name and the parents were assured of confidentiality.

Questionnaires and informal interviews were conducted with teachers who provided a case history and information on the participants, which was very relevant to the study. The projective drawings used in this research were the human figure drawing (HFD), self-portrait (SP), kinetic figure drawing (KFD) and own choice drawing (OCD).

\section{Procedure}

The following sequence of drawings was conducted by each participant

I. Human figure drawing (HFD)

2. Self-portrait (SP)

3. Kinetic family drawing (KFD)

4. Own choice drawing (OCD)

\section{Results}

Qualitative data collected was scored, coded, checked and responses were tabulated in the following frequency tables:

Human figure drawings (HFD)

Table I shows a breakdown of the emotional indicators on the HFD's by the experimental group (A) and control group (B). 
Table I Emotional Indicators on HFD's of the experimental and control group

\begin{tabular}{|c|c|c|}
\hline \multicolumn{3}{|l|}{$N=40$} \\
\hline Emotional Indicators & Group A & Group B \\
\hline Poor integration & I & 0 \\
\hline Shading of face & I & I \\
\hline Shading of body, limbs & 0 & 0 \\
\hline Shading of hands, neck & 0 & 0 \\
\hline Asymmetry of limbs & 2 & I \\
\hline Slanting figure & 3 & I \\
\hline Tiny figure & 3 & 0 \\
\hline Big figure & 4 & 0 \\
\hline Transparencies & I & 4 \\
\hline Tiny head & 0 & 0 \\
\hline Crossed eyes & 0 & 0 \\
\hline Teeth & 4 & I \\
\hline Short arms & 6 & 4 \\
\hline Long arms & 0 & 0 \\
\hline Arms clinging to body & 0 & 0 \\
\hline Big hands & 0 & 0 \\
\hline Hands cut off & 4 & I \\
\hline Legs together & 0 & 0 \\
\hline Genitals & 0 & 0 \\
\hline Monster, grotesque & 4 & 0 \\
\hline Three figures & 0 & 0 \\
\hline Clouds & 0 & 0 \\
\hline No eyes & 0 & 0 \\
\hline No nose & I & I \\
\hline Big Mouth & I & I \\
\hline No body & 0 & 0 \\
\hline No arms & 0 & 0 \\
\hline No legs & 0 & 0 \\
\hline No feet & I & 0 \\
\hline No neck & 2 & I \\
\hline
\end{tabular}

Table I indicates that six of the items (poor integration, tiny figure, monster, teeth and no feet) were found exclusively in the protocols of the experimental group. Five items (asymmetry, slanting, short arms, hands cut off and no neck) were found in both experimental and control groups' protocols but were more frequently validated by the experimental group participants.

The frequency of three items concerning shading of face, no nose and no mouth was equal for both groups' protocols. Transparency indication was found more often on protocols of the control group than the experimental group. Fifteen HFD items were not present on either the experimental or control group protocols.

The four items of big figure, teeth, hands cut off and monster/grotesque were found to be more common on protocols of the experimental group than the control group.

Inkanyiso, Jnl Hum \& Soc Sci 2009, I(I) 
According to Koppitz (1968), emotional indicators must be considered compositely for diagnostic significance. Thus the total number of emotional indicators for each subject's HFD was considered important. Table 2 shows the number of emotional indicators on HFDs of the experimental group in comparison to the control group.

Table 2 shows that only one (5\%) of the 20 participants in the experimental group had no emotional indicators compared to nine $(45 \%)$ control group participants. In the experimental group five participants had more than two emotional indicators compared to none $(0 \%)$ in the control group.

Table 2 Number of emotional indicators on HFDs of experimental group and control group. N-40

\begin{tabular}{|l|l|l|}
\hline Number of Emotional Indicators & Group A & Group B \\
\hline 0 & I & 9 \\
\hline I & 8 & 6 \\
\hline 2 & 6 & 5 \\
\hline 3 & 3 & 0 \\
\hline 4 & I & 0 \\
\hline 5 & I & 0 \\
\hline & 20 & 20 \\
\hline
\end{tabular}

Self-portrait (SP)

Table 3 shows emotional indicators of the experimental group and control group on self portraits. $N=40$

Table 3 Emotional indicators on self portraits of the experimental group and control group.

\begin{tabular}{|c|c|c|}
\hline Emotional Indicators & Group A & Group B \\
\hline Poor integration & I & 0 \\
\hline Shading of face & 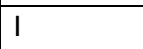 & 0 \\
\hline Shading of body, limbs & $I$ & 2 \\
\hline Shading of hands, neck & 0 & $I$ \\
\hline Asymmetry of limbs & 2 & 0 \\
\hline Slanting figure & 4 & 1 \\
\hline Tiny figure & 3 & 0 \\
\hline Big figure & I & 0 \\
\hline Transparencies & 0 & 4 \\
\hline Tiny head & 0 & 0 \\
\hline Crossed eyes & $\mathrm{I}$ & 0 \\
\hline Teeth & 3 & $I$ \\
\hline Short arms & 6 & 3 \\
\hline Long arms & 0 & 0 \\
\hline Arms clinging to body & 1 & 0 \\
\hline Big hands & 0 & 0 \\
\hline Hands cut off & 5 & 1 \\
\hline Legs together & 0 & 1 \\
\hline Genitals & 0 & 0 \\
\hline Monster, grotesque & 3 & 0 \\
\hline Three figures & 0 & 0 \\
\hline Clouds & 0 & 0 \\
\hline No eyes & 0 & 0 \\
\hline No nose & 0 & 0 \\
\hline No Mouth & 0 & 0 \\
\hline No body & 0 & 0 \\
\hline No arms & 0 & 0 \\
\hline No legs & 0 & 0 \\
\hline No feet & 1 & 0 \\
\hline No neck & 0 & 0 \\
\hline
\end{tabular}


Table 3 shows that nine of the items (poor integration, shading of face, asymmetry, tiny figure, big figure, crossed eyes, arms clinging to body. monster/grotesque and no feet) were found exclusively in protocols of the experimental group. Four items (slanting figure, teeth, short arms and hands cut off) were present in both groups' protocols but more common on the experimental group protocols. Transparencies and shading of hands and neck were found exclusively on the control group protocols.

Table 4 Number of emotional indicators on self portraits of the experimental group and control group, N-40

\begin{tabular}{|l|l|l|}
\hline Number of Emotional Indicators & Group A & Group B \\
\hline 0 & 3 & II \\
\hline$I$ & 5 & 5 \\
\hline 2 & 9 & 4 \\
\hline 3 & 2 & 0 \\
\hline 4 & 0 & 0 \\
\hline 5 & 1 & 0 \\
\hline & 20 & 20 \\
\hline
\end{tabular}

Eleven of the 20 participants (55\%) in the control group had no emotional indicators on their protocols compared to three $(15 \%)$ in the experimental group. Twelve $(60 \%)$ of the experimental group participants displayed two or more of the emotional indicators on their protocol as compared to only $4(20 \%)$ in the control group.

HFD and Self-portraits analysis

In protocols for both HFDs and SPs the number of protocols with two or more emotional indicators was always higher in the experimental group than in the control group. The total number of protocols from the experimental group with no emotional indicators was $4(10 \%)$ as compared to $20(50 \%)$ protocols in the control group. The total number of protocols with one emotional indicator was found to be $13(33 \%)$ in the experimental group with 12 (30\%) in the control group. As discussed by Koppitz (1968) the presence of only one emotional indicator implies absence of serious emotional problems. For two or more emotional indicators, a difference between the two groups was evident. The total number of protocols with two or more indicators was 23 (58\%) for the experimental group and only 8 (20\%) for the control group. As discussed by Koppitz (1968) two or more emotional indicators are suggestive of emotional problems including interpersonal problem.

Kinetic family drawings

Analysis showed that it was easier to differentiate between the two groups as they were found exclusively in protocols of the experimental group participants. These variables included compartmentalization, unexpected description of figure actions, no face and position of figure with respect to safety. As revealed in this study, these variables could be regarded as an important screening measure when assessing for psychopathological family dynamics, which can occur in bereaved families.

Own choice/spontaneous drawings

The measured own choice/spontaneous drawings was not effective in differentiating the experimental from the control group participants.

In this study the spontaneous or own choice drawing served the purpose of relieving tension or relaying wishes rather than differentiating between the experimental and control groups. Davies's (1995) view is validated, in that drawings can serve as a mechanism of distraction from grief work.

\section{Discussion}

The findings of this study provided evidence that children do indeed go through a process of grief. Grief symptoms reported by bereaved children were confirmed by parental reports. The emotional indicators on human figure drawings and other variables on kinetic family drawings, reflected symptoms that characterized bereaved individuals.

Findings also supported the concept that grief is a unique process (Hemmings, 1995). While grief symptoms were similar in most of the bereaved children, the grief process was not identical in nature.

This study was able to support the assumption that children's drawings provide sufficient information on emotional state to distinguish a bereaved child from a child who is not suffering from grief. As noted by Malchiodi (200I) children's drawings can reveal thoughts, feelings and psychological wellbeing reflecting the child's persona.

As discussed by Cobia and Brazerton (1994) projective drawings are amongst the most commonly used assessment tools for socio-emotional assessment. As revealed in this research, the human figure drawings (HFDs) and self portraits Inkanyiso, Jnl Hum \& Soc Sci 2009, I(I) 
(SP) were able to distinguish the bereaved group participants from the non-bereaved group participants. Big figure, teeth, monster/grotesque figure, hands cut off and slanting figure were the emotional indicators which indicated a large difference (when HFDs and self portraits were separately considered). Those emotional indicators found exclusively on the experimental group protocols were found to be diagnostically important and they could assist in the understanding of the inner world of a bereaved child.

The kinetic family drawings could not significantly differentiate the experimental from the control group but were found to be invaluable in providing insight into the family dynamics. Variables identified, such as omissions, were consistent with psychopathological interpersonal relationships within bereaved families.

Own choice/spontaneous drawings also could not significantly distinguish experimental group from control group participants.

\section{Conclusion}

The following conclusion can therefore be drawn from the research. Human figure, self portrait and kinetic family drawing provide a composite picture for gaining primary insight into the inner world of the bereaved child and the bereaved child's family dynamics. Own choice drawings can be administered to assess a child's feelings toward bereavement once this has been identified.

Projective questions following completion of any projective drawing were an invaluable additional form of assessment. When in doubt, check information out by asking the child directly. The current research revealed that projective drawings have an important role in psychology. Projective drawing research is often criticized for selective reporting, where only significant results are found (Garb, Wood \& Nezworski, 2000) and distortion in analysis, where indicators are not clearly defined (Abraham in Lev-Wiesel, 1999). In this study results are shown, guidelines for scoring used, and technique indicators were clearly defined. Since the sample for the present study was small and confined to a limited geographic area, future studies exploring similar concepts with larger samples would allow for the generalization of results. Future studies should have independent raters for human figure drawings, self portraits and kinetic family drawings to increase reliability.

\section{References}

Bailey, K.D. (1978). Methods of social research. New York: The Free Press

Bowlby, J. (1980). Attachment and loss (Vol.3): Loss, sadness and depression. London: The Hogarth Press.

Burns, R.C. (1982). Self-growth in families. New York: Brunner Mazel.

Cantlay, L. (1996). Defecting child abuse: recognizing children at risk through drawings. Santa Barbara: Holly Press

Case, C. (1987). A search for meaning: loss and transition in art therapy with children. In J. Dailey (Eds.). Images of Art Therapy. London: Tavistock.

Christ, G.H.; Siegel, L.; Masagno, F.P. \& lan Gosch, D. (1991). A preventive intervention program for bereaved children: problems of implementation. American Journal of Orthopsychiatry 61(2) I68-I 78.

Cobia, D.C. \& Brazelton, E.W. (1994). The application of family drawing tests with children in remarriage families: understanding familial role. Elementary School Guidance and Counselling, 29 (2), 129-137.

Davies, C.B. (1995). The use of art therapy and gro up process with grieving children. In Smith, S.C. \& Pennells, M. (Eds.). Interventions with Bereaved children. London: Jessica Kinsle.

Forrest, M. \& Thomas, C.V. (199I). Group intervention with bereaved children. In Papadatou, D. \& Papadatos, C. (Eds.). Children and Death. New York: Hemisphere.

Garb, H.N.; Wood, J.M.; Nezworski, M.T. (2000). Projective techniques and the detention of child sexual abuse. Child Maltreatment, 5 (2), 16 I- 168.

Golomb, C. (1992). The child's creation of a pictorial world. Berkeley and Los Angeles: University of California Press.

Hammand, L. C. \& Grantt, L. (1998). Using art in counselling: Ethical considerations. Journal of Counselling and Development, 76 (3), $|76-2| 1$.

Harris, D.B. (1963). Children's drawing as measure of intellectual maturity. New York: Harcourt, Brace and World.

Hemmings, P. (1995). Communicating with children through play. in Smith, S.U. \& Pennells, M. (Eds.). Interventions with bereaved children. London: Jessica Kingsle.

Kelly, S. (1985). Drawings: critical communications for sexually abused children. Pediatric Nursing. II, 42I-426.

Kelly, S. (1984). The use of art therapy with sexually abused children. Journal of Psychosocial Nursing and Mental Health Services, $22(12), 12-18$.

Klepsch, M. \& Logic, I. (1982). Children draw and tell. New York: Brunner/Mazel.

Koppitz, E.M. (1968). Psychological evaluation of children's human figure drawings. New York: Grune \& Stratton.

Koppitz, E.M. (1983). Psychological evaluation of human figure drawings by middle school pupils. New York: Grune \& Stratton.

Lev-Wiesel, R. (1999). The use of the Machover draw a person test in detecting adult survivors of sexual abuse; a pilot study. American Journal of Art Therapy, 37 (4), I06-II 2.

Malchiodi, C.A. (200I). Using drawings as intervention with traumatized children. Trauma and Loss: Research and Interventions, Volume I (I). pages 2I - 28.

Mayekiso, T.V. (1 982). A psychological evaluation of the human figure drawings of a sample of black std $V$ school children. Alice: University of Fort Hare. 
McMahon, L. (1992). The handbook of play therapy. London: Tavistock/Routledge. Reaves, C.C. (1992). Quantitative research for behavioural sciences. Canada: John Wiley and Sons, Inc.

Schweigert, W.A. (1988). Research methods in psychology: a handbook. New York: Brooks/Cole Publishing Company.

Siegel, I. (1960). The application of projective techniques in research with children. In Rabin, A.I. \& Haworth, M.R. (Eds.). Projective Techniques with Children. New York: Grune \& Stratton.

Siegel, K.: Mesagno, F.R. \& Christ, G. (1990). A prevention program for bereaved children. American Orthopsychiatric Association, 60 (2), 168-175.

Winnicott. D. (197I). Playing and reality. New York: Basic Books.

Worden, J.W. (1986). Grief counselling and grief therapy. London: Tavistock. 